\title{
Analysis of Repair Level for Missile Based on Reliability Centered Maintenance
}

\author{
Ma Ning, Xiang Yujun \\ Department of Aviation Ammunition Engineering, The First Aeronautic Institute of the Air Force, \\ Xinyang, 464000, China.
}

Keywords: missile; RCMA; LORA; decision tree model.

\begin{abstract}
A research of Level of Repair Analysis (LORA) for missile's equipments to improve its maintainability is proposed. The preventive maintenance mode of a new missile system is determined via using RCMA (Reliability Centered Maintenance Analysis) and performed under the combination with its maintenance actuality. A decision tree model of LORA is established as a result of the analysis on the meaning, structure, non-economic influence factors and analytical procedure of LORA to modify the existing missile maintenance system, as well as reducing the maintenance cost and difficulities.
\end{abstract}

\section{Introduction}

With more new type missiles were fitted out in force gradually, the demand of missile maintenance is highly increased due to armament's complexities and technologies. A whole normative and complete maintainability system and criterion of normality is not to be established because of lack of scientific and feasible maintenability analysis. Currently, daily servicing, management and fault detection are the major task for new type equipment. The weak ability of maintenance becomes the bottleneck for the improvement of maintainability and work efficiency. Consequently, it is necessary to set up a new reasonable repair level which is combined with comprehensive analysis on various related factors

LORA (level of repair analysis) is a process of analysis and planning for equipment support system [1]. It is normally used to derive a repair level that is feasible and cost-efficiency optimal for the equipment. RCMA on a certain type of missile in service in PLA was given in this paper, the failure mode and their criticality was determined, which laid a foundation and provided inputs for LORA. Furthermore, noneconomic LORA analysis on the equipment during the phase of use and support was done to derive the decision tree model.

The paper is organized as follows. In the next section, the analytic method which used in this paper is proposed, and some definitions and assumptions are given. Section 3 presents the reliability centered maintenance analysis procedures. In Section 4, the missile LORA model based on RCMA is discussed, and decision tree model of missile LORA is presented. Finally, the conclusion is given in section5.

\section{Level of repair analysis}

According to the definition in the session 'LORA' in GJB2961-97[2], LORA was defined as "the process of economic or noneconomic analysis for a product bound to have failures in its lifetime so as to get its proper level of repair or the decision of disposal”. LORA is an important part of can identify not only the repair sites or disposal location for the equipment and its components, but also the support equipment needed, spare parts storage, maintenance crew needed and their technical capabilities, and training and etc. for different levels of repair institutions.

The aim for LORA is to decide whether or not the product needs repairing and in which level of repair institution the product should be repaired, i.e., to allocate maintenance tasks and maintenance resources and to decide the responsibilities of each repair level reasonably[3].

Through economic and noneconomic analysis of LORA, the best level for repair action was determined for the defective components of the equipment. Regarding the different phases the 
equipment is in its life time, LORA can be divided into LORA in development phase and LORA in use and support phase [4]. In this paper, noneconomic LORA in use and support phase of one certain missile equipment was discussed.

\section{RCMA on missile equipment}

RCMA is one system analysis method that is used to determine the necessity of preventive maintenance for the equipment and to optimize maintenance system. It is aimed to find out all possible failures that may occur in the equipment system and their reasons and causes by carrying out functional and failure analysis [5]. In RCMA, a systematic logic decision method will be used to identify preventive maintenance strategies for each failure. According to GJB1378A-2007[6], RCMA for weapon equipment includes RCMA for system and equipment, structure RCMA, regional inspection and analysis and RCMA results.

As for a missile, its primary components include electro-optic, electromechanical electronic items and structural components including the projectile body, sections connectors and internal fastening device. Sections for missiles are sealed to avoid exposure of their internal structures. In most cases, it is not allowed to be opened in case of random failures. When missiles are delivered to flight squadrons, they are normally sealed in their packages and stored in warehouses. Therefore, the structure will rarely be affected by the environment. Structural RCMA for missiles mainly focuses on structural parts of the missile body while internal inspection for the missile is rarely required. So, missile’s RCMA mainly includes system and equipment RCMA.

Aims for RCMA of missile system and equipment are as follows:

1. Find items that need preventive maintenance and those needless or unimportant items.

2. FMECA should be carried out for confirmed important items to identify the possible failures and their reasons, failure modes and their severity.

3. When design modification is not feasible, standard logic decision methods should be used to determine preventive strategies. Procedure for missile system and equipment RCMA is shown as follows:

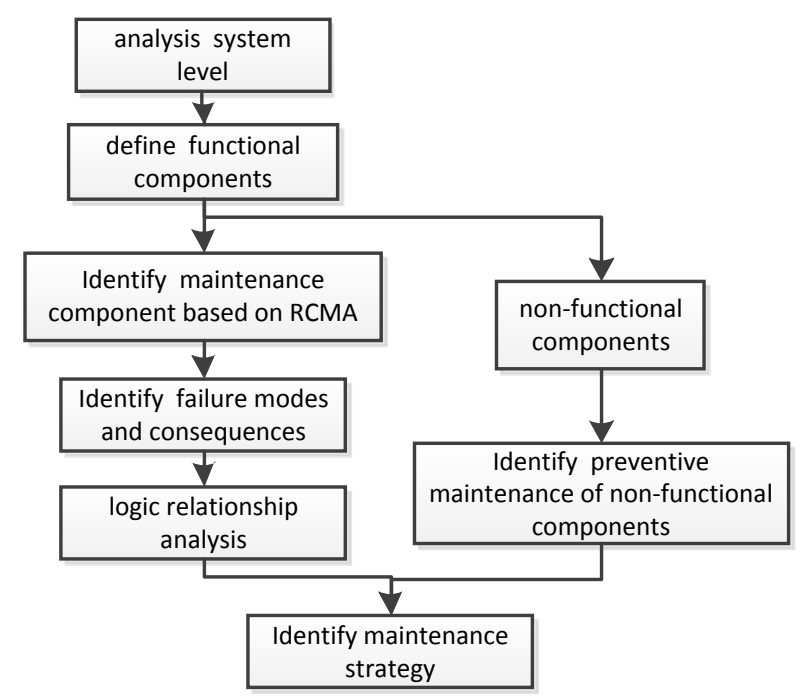

Fig.1: RCMA procedure of missile equipment and system

\section{System indenture categorization and important items determination}

Important items of missiles refer to subsystems and modules of the missile. For almost every part of a missile is detachable or replaceable, any failure occurring from any part would cause malfunction of the missile. So every missile (module) part can be regarded as important items for RCMA. The indenture categorization of a missile system and equipment should be analyzed follow the order of its assembly from top to end.Fig.2 shows the structure of missile system. 


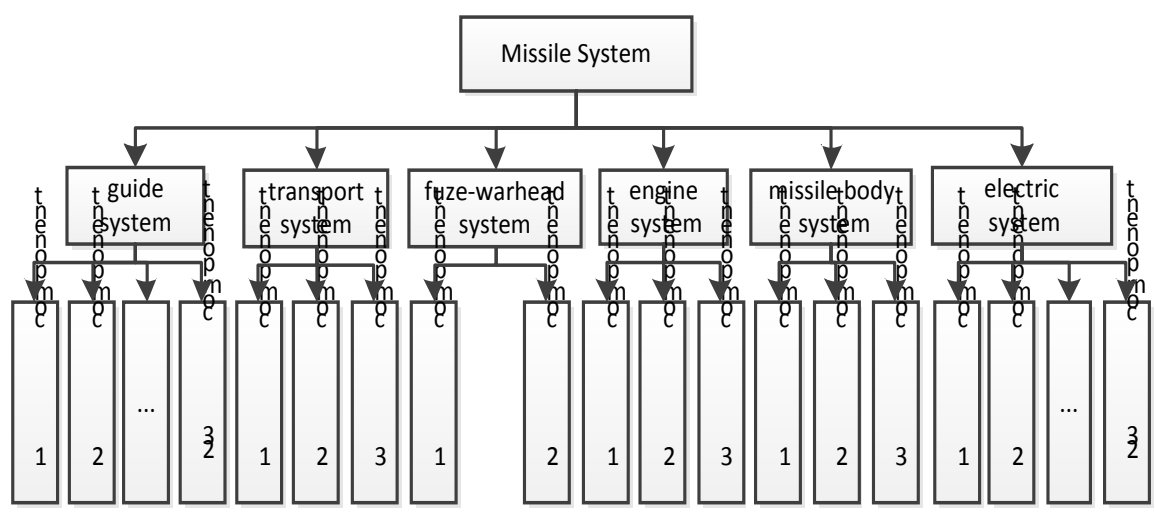

\section{Failure mode and effect analysis.}

Fig.2: Structure of missile system

FMECA (Failure Mode Effect and Criticality Analysis, FMECA) is an analysis methodology by which all potential failure modes are found, the causes and effects of failure modes are analyzed, critical failure modes are selected and methods to mitigate or remove the effects of critical failure modes are provided[7]. It will be done for equipment of missile RCMA so as to identify failure modes, reasons and severity to lay a solid foundation for maintenance and support system planning. Table.1 shows the potential or normal failure modes and phenomenon of missile body[8].

Table.1 Define failure mode of missile body

\begin{tabular}{|c|l|}
\hline Failure mode & \multicolumn{1}{|c|}{ Phenomenon \& explain } \\
\hline $\begin{array}{c}\text { damage } \\
\text { chalitative } \\
\text { change }\end{array}$ & $\begin{array}{l}\text { physical quality and chemical quality, wear, } \\
\text { temperature is too high, temperature is too low }\end{array}$ \\
\hline position change & vibration, unable keep normal position \\
\hline leakage & internal or external leakage of gas,liquid,solid \\
\hline $\begin{array}{c}\text { parameters } \\
\text { overrun }\end{array}$ & $\begin{array}{l}\text { DC resistance, insulation resistance, test } \\
\text { parameter overrun upper limit or lower limit }\end{array}$ \\
\hline $\begin{array}{c}\text { abnormal } \\
\text { indication }\end{array}$ & indicate error, indicate ambiguity \\
\hline $\begin{array}{c}\text { abnormal } \\
\text { electrical } \\
\text { property }\end{array}$ & short circuit, open circuit, electrical leakage \\
\hline other & other fault modes \\
\hline
\end{tabular}

A criticality class can be determined for each failure mode. Table.2 shows the definition of criticality class for failure mode[9].

Table.2 Define criticality class for failure mode

\begin{tabular}{|l|l|}
\hline \multicolumn{1}{|c|}{ Criticality class } & \multicolumn{1}{|c|}{ Criticality definition } \\
I(catastrophic) & $\begin{array}{l}\text { A failure which may cause death or } \\
\text { weapon system loss. }\end{array}$ \\
\hline Category II(critical) & $\begin{array}{l}\text { A failure which may cause severe } \\
\text { injury,major property damage, or major } \\
\text { system damage which will result in } \\
\text { mission loss. }\end{array}$ \\
\hline Category III(marginal) & $\begin{array}{l}\text { A failure which may cause minor injury, } \\
\text { minor property damage, or minor system } \\
\text { damage which will result in delay or loss } \\
\text { of availability or mission degradation. }\end{array}$ \\
\hline Category IV(minor) & $\begin{array}{l}\text { A failure not serious enough to cause } \\
\text { injury,property damage, or systenm } \\
\text { damage, but which will result in }\end{array}$ \\
\hline
\end{tabular}




\section{Preventive maintenance type determination.}

unscheduled maintenance or repair.

Seven types of preventive maintenance tasks should be included [10]:

i) Service. Service is performed in daily use or maintenance for missiles, including periodical inspections for depots environment and package air tightness.

ii) Usage inspection. Inspections should be performed according to maintenance plans so as to find potential failures.

iii) Monitoring. Normal monitoring for missiles in use should be used to detect potential failures of products. The contents of normal monitor include before use inspection or monitoring for instruments, i.e.

iv) Function detection. Quantitative detection for missile technical parameters making sure that all parameters are within range for missions. v) Periodic overhaul. Restoration maintenance work can be performed on mechanical parts in missiles which have obvious wastage characteristics.

vi) Periodic disposal. Type of work can be performed on non-repairable components and severely worn components that repair are not applicable, such as initiating devices for missiles. They will be used only once and will be disposed of once the time of storage is full.

vii) Comprehensive work. Two or more the above mentioned work types combined together.

\section{Missile LORA models}

\section{Determination of missile repair level.}

Concerning the complexity of missiles and their maintenance level, two stage maintenance systems are used on missile system maintenance: operation-level maintenance and deport-level maintenance[11].Operation-level maintenance is normally carried out on the operation spot by the crew in operational and maintenance wing, including daily servicing, detection, examination; Several equipment for detection and repair equipment, maintenance spare parts are equipped on the operation-level maintenance institutions. Deport-level maintenance is carried out by the ordnance service depots and the manufacturing contractors. All maintenance tasks should be able to be accomplished in this level of maintenance institution, including major parts repair, spare parts manufacturing and supply, damaged parts repair and reproduction. Maintenance tasks can be done in the depots or at the flight line.

\section{Noneconomic factors.}

The following noneconomic factors should be considered in the LORA for missiles given use and maintenance features of missiles [12-13]:

i) Safety. Safety must be considered for weapons like missiles that includes engines and warheads.

ii) Present maintenance plan. The present maintenance plan and maintainability of different levels of military maintenance units should be considered.

iii) Support equipment. Testing equipment and special tools for maintenance are equipped on the proposed level of repair or not.

iv) Package, storage, loading/unloading, and transport. Special needs for package, transport, load/unload and storage. (temperature, moisture, climate, electrostatic proof and etc.)

v) Maintenance crew specialty and technical capabilities. Maintenance crew specialty configuration and abilities satisfy a certain level of repair.

vi) Facilities. Special facilities, repair craft for a certain repair level.

vii) Maintenance complexity. Complex maintenance, craft requirements satisfy a certain repair level.

viii) Confidentiality. Confidentiality occurs at specific levels of maintenance.

\section{LORA procedure.}

RCMA results should be consulted in LORA for missiles. Noneconomic analysis should be done respectively to determine maintenance task level for items at different indentures [14]. LORA procedure is shown in Fig.3. 


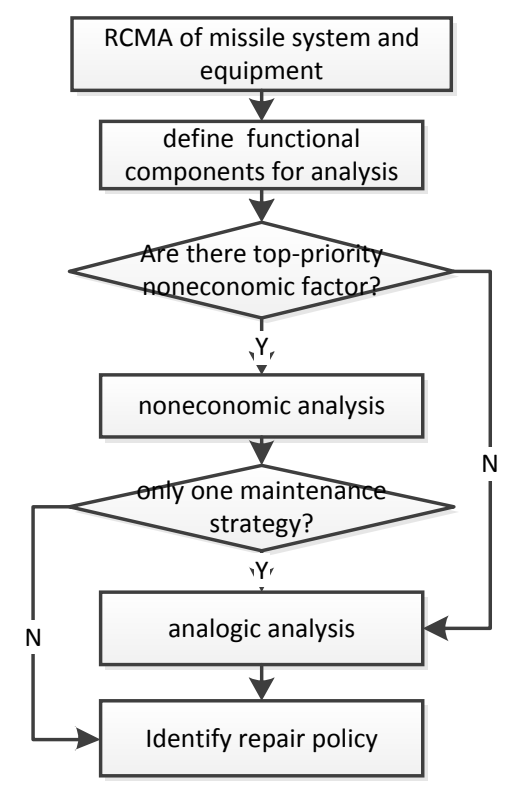

Fig.3: Procedure of missile LORA

Some maintenance tasks are affected by multiple noneconomic factors in analysis. Then, comprehensive evaluation should be done to determine a feasible maintenance level. If noneconomic analysis is not enough to determine the maintenance level, comprehensive analysis should be carried out.

\section{Missile LORA decision tree model}

Decision tree analysis is a traditional methodology in LORA. Decision tree analysis can be used to reduce analysis work in practice [15]. The decision tree model is established as shown in Fig.4. Primary level of maintenance can be determined via LORA decision tree model.

From Fig.4, there are three knots for decision making: the first knot will result in operation-level maintenance if the answer is "yes". This level of maintenance includes only minor work for trouble shooting; the second knot will result in repair work as replacement, normally at operation-level; the third knot will result in deport-level maintenance which requires higher level of repair or complex repair equipment.

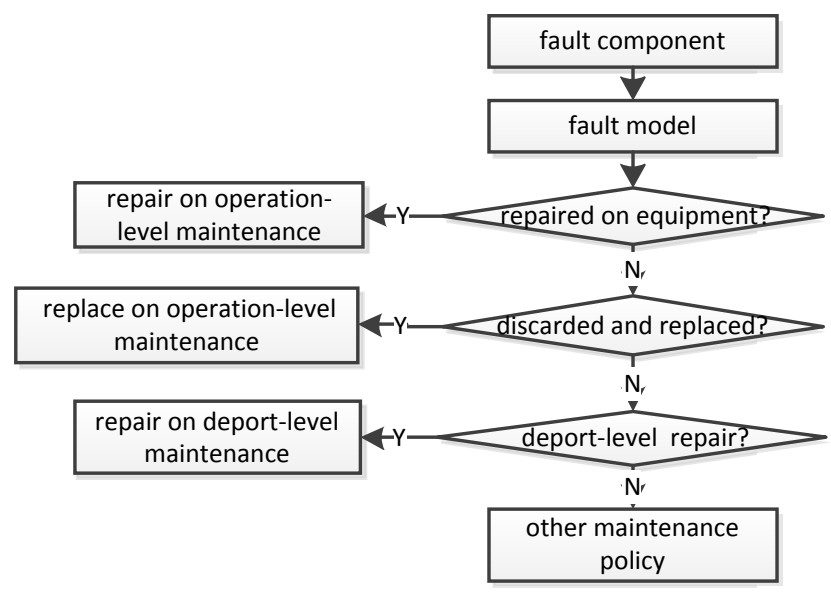

Fig.4 Decision tree model of missile LORA

\section{Conclusions}

The noneconomic LORA decision tree model in support phase based on the maintenance's status quo of PLA's new missiles was established via RCMA on missile system. Scientific analysis on missile faulted-parts' repair level was carried out to obtain maintenance plan or provide possible theoretic foundation and reference for decision formulating.

\section{References}


[1] Gutin G, Rafiey A\&Yeo A. Level of repair analysis and minimum cost homomorphism of graphs.Discrete Applied Mathematics, 154(6),pp.881-889,2006.

[2] GJB 2961-97,Level of repair analysis.

[3] Basten R.J.I, Schutten J.M.J\& Heijden M.C.V.D. An efficient model formulation for level of repair analysis. Annals of Operations Research, 172(1),pp.119-142,2009.

[4] Haritha Saranga, Dinesh Kumar U. Optimization of aircraft maintenance/support infrastructure using genetic algorithms-level of repair analysis. Annals of Operations Research, 143,pp.91$106,2006$.

[5] Lu Xiao-Hong, Jia Zhen-Yuan\&Gao Sheng-Nan.Failure Mode Effects and Criticality Analysis (FMECA) of Circular Tool Magazine and ATC. Anal and Preven, 13, pp.207-216,2013

[6] GJB 1378A-2007, Equipment repair analysis based on RCM.

[7] Xu K, Tang L C\& Xie M. Fuzzy assessment of FMEA for engine systems. Reliability Engineering and System Safety,75(1),pp.17-29,2002.

[8] Zhao Da-Lei, Huang Ding-Dong, Li Mu-Yi\& Wang Zhe.LORA for Certain Missile-borne Equipments. Computer and Modernization,7,pp.65-68,2013.

[9]J.H.KIM,H.Y.JEONG \& J.S.PARK. Development of the FMECA process and analysis methodology for railroad systems. International Journal of Automotive Technology, 10(6), pp. 753-759,2009.

[10] Zhao Jjian-Zhong, Ding Guang-Bing\& Guo Hong-Chao . Application maintenance on LORA based on RCM in missile equipment maintenance. Quality and Reliability, 157(1),pp.10-13,2012.

[11] Chen Xue-Chu.Modern Maintenance Theory. Beijing: National Defense Publishing service, 2003.

[12] Wang Yuan-Da. Methodology of LORA. Fire control and command control, 33(4),pp. 13,2008

[13] Basten R.J.I, Heijden M.C.V.D.Schutten J.M.J. A minimum cost flow model for level of repair analysis. International Journal of Production Economics, 133(1),pp.233-245,2011.

[14]Huang Jian-Xin. SAM equipment LORA model in service. Tactical missile technologies, 6,pp.31-34. 2005.

[15]Xie Xin-Lian, Huo Wei-Wei\&Xu Hao.Analysis of repair level for ship equipment based on decision tree.Ship Engineering,31(6),pp.84-87,2009. 